\title{
Long-Term Performance Data and Analysis of CIS/CIGS Modules Deployed Outdoors
}

Conference Paper NREL/CP-520-42856

November 2008

J.A. del Cueto, S. Rummel, B. Kroposki, and A. Anderberg

Presented at SPIE Optics + Photonics 2008 San Diego, California

August 10-14, 2008
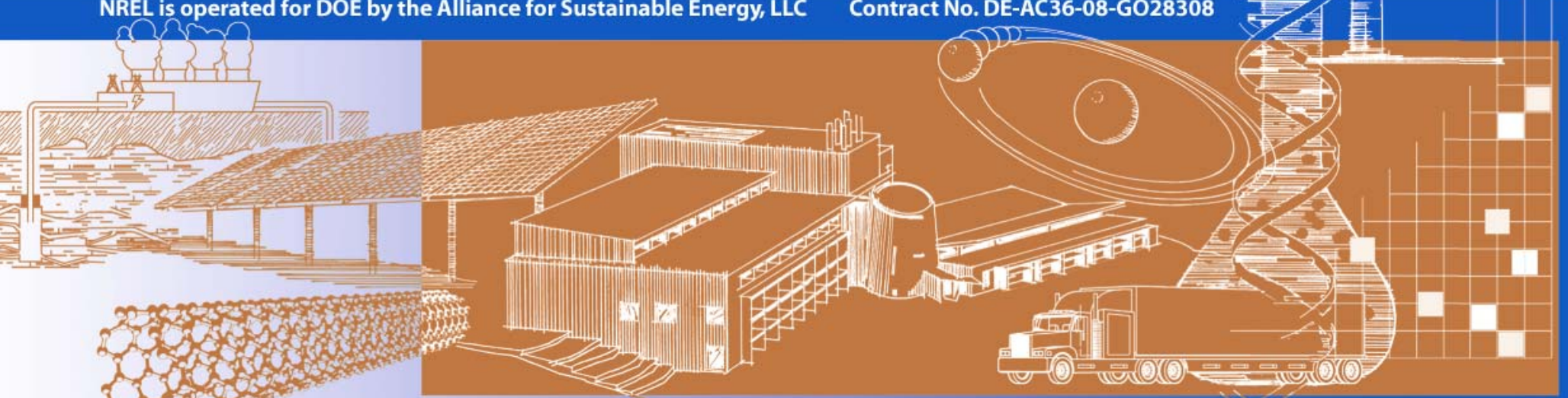


\section{NOTICE}

The submitted manuscript has been offered by an employee of the Alliance for Sustainable Energy, LLC, (ASE) a contractor of the US Government under Contract No. DE-AC36-08GO28308. Accordingly, the US Government and ASE retain a nonexclusive royalty-free license to publish or reproduce the published form of this contribution, or allow others to do so, for US Government purposes.

This report was prepared as an account of work sponsored by an agency of the United States government. Neither the United States government nor any agency thereof, nor any of their employees, makes any warranty, express or implied, or assumes any legal liability or responsibility for the accuracy, completeness, or usefulness of any information, apparatus, product, or process disclosed, or represents that its use would not infringe privately owned rights. Reference herein to any specific commercial product, process, or service by trade name, trademark, manufacturer, or otherwise does not necessarily constitute or imply its endorsement, recommendation, or favoring by the United States government or any agency thereof. The views and opinions of authors expressed herein do not necessarily state or reflect those of the United States government or any agency thereof.

Available electronically at http://www.osti.gov/bridge

Available for a processing fee to U.S. Department of Energy and its contractors, in paper, from:

U.S. Department of Energy

Office of Scientific and Technical Information

P.O. Box 62

Oak Ridge, TN 37831-0062

phone: 865.576 .8401

fax: 865.576 .5728

email: mailto:reports@adonis.osti.gov

Available for sale to the public, in paper, from:

U.S. Department of Commerce

National Technical Information Service

5285 Port Royal Road

Springfield, VA 22161

phone: 800.553 .6847

fax: 703.605.6900

email: orders@ntis.fedworld.gov

online ordering: http://www.ntis.gov/ordering.htm 


\title{
Long-Term Performance Data and Analysis of CIS/CIGS Modules Deployed Outdoors
}

\author{
J.A. del Cueto*, S. Rummel, B. Kroposki, A. Anderberg \\ National Renewable Energy Laboratory (NREL), 1617 Cole Boulevard, Golden, CO 80401, USA
}

\begin{abstract}
The long-term performance data of copper indium diselenide (CIS) and gallium-alloyed CIS (CIGS) photovoltaic (PV) modules are investigated to assess the reliability of this technology. We study and report on numerous PV modules acquired from two manufacturers (A and B), deployed at NREL's outdoor test facility (OTF) in various configurations in the field: some are free standing, loaded with a fixed resistance and periodically tested indoors at STC; other modules are connected to data acquisition systems with their performance continuously monitored. Performance is characterized using current-voltage (I-V) measurements obtained either at standard test conditions or under real-time monitoring conditions: the power parameters plus other factors relating to quality like diode quality factors or series resistance are analyzed for changes against time. Using standard diode analysis to determine the sources of degradation indicates that CIS modules can exhibit between moderate and negligible degradation, with the dominant loss mode being fill factor declines along with decreases in open-circuit voltage, for illumination intensities near 1-sun. At lower intensities, current losses can appear appreciable. The real-time performance data also indicate that fill factor loss is the primary degradation mode, generally as a result of increases in series resistance.
\end{abstract}

Keywords: Long-term performance, reliability, photovoltaic modules, CIS, CIGS

\section{INTRODUCTION}

The highest performing thin-film PV devices are those based on copper indium-gallium diselenide (CIGS) at approximately $19.9 \%$ as measured at standard test conditions (STC) [1]. The best efficiencies obtained from large-area PV modules of this technology are about $12 \%$. However, the long-term stability of CIS/CIGS modules is a key issue in the reliability of this technology that needs to be addressed. Performances changes have been observed in CIGS devices when subjected to damp-heat stress and/or illumination or bias as noted: decreases in open-circuit voltage (Voc) via changes in doping density; conduction band offsets between CIS absorber and cadmium sulfide (CdS) window layers [2]; losses in Voc due to defect-induced recombination and fill factor (FF) loss by type conversion at the CdS/CIGS interface brought about by degradation of the zinc oxide ( $\mathrm{ZnO})$ transparent conductive oxide (TCO) [3]; defects in and degradation of the $\mathrm{ZnO}$ and $\mathrm{CdS}$ layers, leading to poor conductivity or damage at the CdS/CIGS interface [4]; and degradation of the top $\mathrm{ZnO}$ or CdS/CIGS interface [5] leading to series resistance increases and FF losses. Most of these cited studies have focused on un-encapsulated CIGS devices. Nevertheless, recent studies on the effects of damp- or dryheat exposure on encapsulated CIGS mini-modules indicate the primary failure mode observed in the test structures entail FF degradation as a result of increases in the series resistance of the top ZnO TCO [6].

\section{EXPERIMENTAL AND ANALYTICAL METHODS}

Either CIS and/or CIGS modules from one manufacturer (type A) were first installed at the OTF beginning in 1988; starting in 2002, CIGS modules from a second manufacturer (type B) were deployed. The scope of this study involves numerous CIS PV modules deployed on three separate configuration testbeds. Even though the A modules are no longer commercially manufactured, we still retain many of them deployed at the OTF. All modules were baseline tested under STC using one or more of three solar simulator testbeds: the SPIRE pulsed-light source, the large-area continuous solar simulator (LACSS), and the standard outdoor measurement system (SOMS). In addition, dark I-V characteristics are measured on representative modules using the LACSS testbed. After baseline testing, these were installed in the field as: 1) single free-standing modules ( $\mathrm{A}$ and $\mathrm{B}$ ) on the long-term exposure rack, loaded with a fixed resistor across the terminals (whose value approximates the optimum load at STC); 2) single modules (A and B) deployed on the Performance and Energy Ratings Testbed (PERT) system situated on the roof of the OTF; or 3) an array of type A 
modules on the high-voltage stress testbed (HVST2) beginning in 2005. The freestanding and/or PERT modules are taken indoors periodically for I-V measurements at STC or under dark conditions and then re-deployed outside.

The PERT and HVST2 modules are mounted on open-air, steel frame racks, inclined at fixed, latitude tilt $\left(40^{\circ}\right)$ with respect to the horizontal, facing due south. Their arrangements are depicted in Fig. 1, showing digital images of PERT system and HVST2 array modules, respectively, in the left and right portions of the figure. The HVST2 array and PERT system modules are electrically connected to programmable electronic loads (PEL) and continuously monitored in situ via separate data acquisition systems (DAS). PERT modules are singularly connected and loaded, one per channel on a multi-channel electronic load interfaced to one DAS. The HVST2 array comprises 24 type-A CIGS modules configured into two separate bipolar strings that consist of 12 series-connected modules with nominally positive or negative 300 VDC open-circuit voltages each. The positive and negative strings of the HVST2 array are each connected to separately controlled channels in a dual-channel PEL interfaced to another DAS. All connections employ a four-wire measurement scheme: two leads to carry the power plus two separate leads to sense the voltages as close to the modules as possible.

The PERT DAS executes I-V traces once every 15 minutes, and at other times actively maintains the modules loaded at their optimum-power point appropriate for the instantaneous lighting and temperature conditions. The HVST2 array DAS also performs I-V traces on each of the strings periodically, and at all other times actively biases each string either at their respective instantaneous optimum-power-point load or at fixed-voltage bias conditions. The HVST2 DAS is capable of and also performs cyclic biasing to fixed voltage levels, whose setpoint is stepped over time to produce square-wave output bias vs. time. The only pertinent difference between PERT and HVST2 module mounting configurations, is that the HVST array modules are erected with their frames electrically isolated from ground through a drop resistor, in order to monitor the high-voltage (HV) leakage currents ensuing from the PV devices' self bias, through the module package insulation, to the mounting anchors; but otherwise the I-V data are monitored and produced similarly to the PERT module data. The PELs used to electrically characterize and bias outdoor modules do not have the capacity to set the bias outside of the voltage range accessible or produced under existing field conditions. In addition, the DAS monitor and record the concurrent ambient meteorological conditions: irradiance with broadband pyranometers, air and module temperatures using type ' $\mathrm{T}$ ' thermocouples, and relative humidity with a capacitance probe. More details of PERT system and/or of outdoor data analysis are described elsewhere [7].
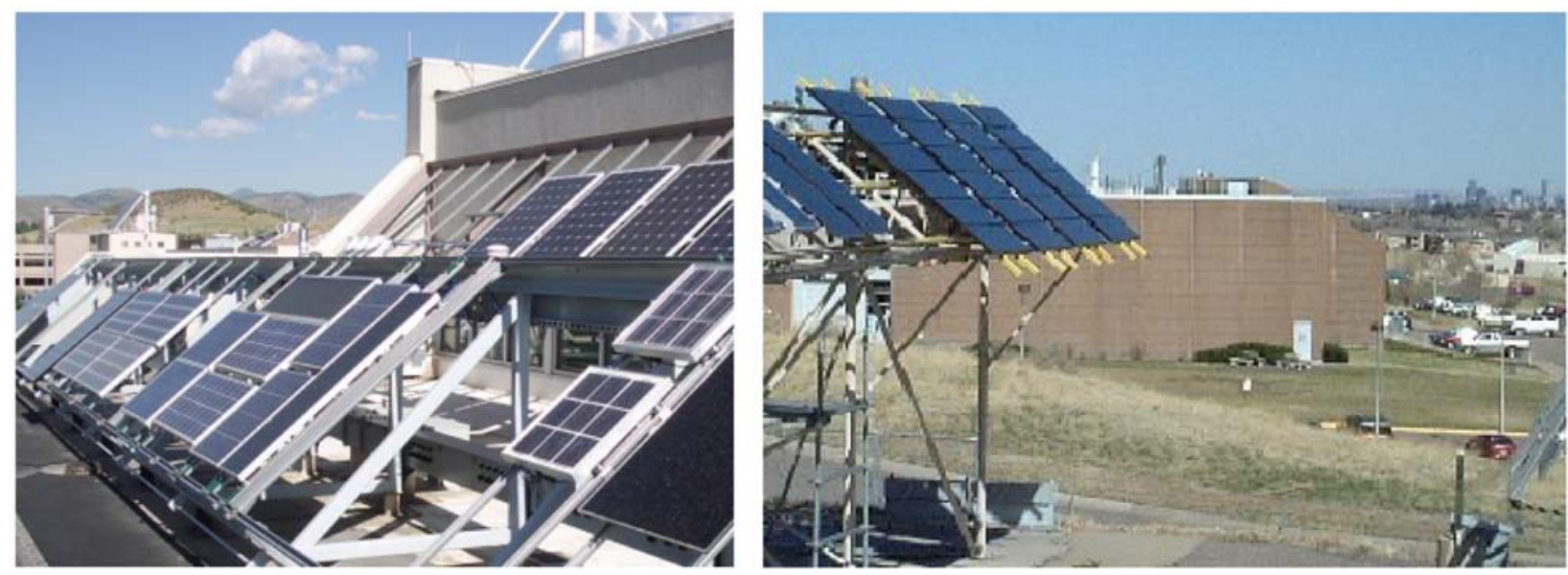

Figure 1. Digital images of the PERT modules at left, looking west; and HVST2 modules at right, viewed east, at the OTF.

Some of the data taken on the LACSS, either at STC or under dark conditions, were further analyzed by normalizing the module voltages and currents to the unit cell level. This was achieved by: dividing the module voltage (V) by the number of series-connected cells; and dividing the current by the area of each unit cell (taken as the module aperture area divided by the number of cells), thereby resulting in current-density $(\mathrm{J})$. The cell areas are approximately $10 \%-15 \%$ larger than the active area - so $\mathrm{J}$ data are correspondingly smaller - due to interconnect and border area losses extant in modules. From LACCS data, device-level parameters such as the series resistance, diode quality factors (A), reverse saturation current density $\left(\mathrm{J}_{0}\right)$, and shunt conductance (Gsh) values are derived via standard diode analysis as cited in the literature [8]: e.g., series-resistance data are derived from the intercept of the locus of slopes of the J-V data (dV/dJ) vs. J, extrapolated to the origin with $1 / \mathrm{J}$ (for dark) or $1 /\left(\mathrm{J}+\mathrm{J}_{\text {Light }}\right.$ ) (for light) characteristics. Using outdoor data, series resistance and diode quality factors were derived by a method also previously cited [9] that involves three steps: 1) obtaining the 
slopes of the I-V curves at open-circuit (Roc) as a function of illumination; 2) performing linear regression of these data against module temperature and segregated by irradiance bins, typically $50 \mathrm{~W} / \mathrm{m}^{2}$ wide, and then evaluating the Roc, Isc data from regression parameters at reference temperature $\left(25^{\circ} \mathrm{C}\right)$ across all illumination levels; and 3$)$ performing linear regression of Roc vs. 1/Isc from which the intercept and slope of the regression produces the series resistance and diode quality factors, subsequently scrutinized for modification with time.

The presented results are organized in the subsections noted: in 3.1 data, taken at STC or in the dark, for the freestanding modules followed by diode analysis, measured using the SPIRE or LACSS; analysis of PERT modules in 3.2, and HVST2 array in 3.3, field data taken across all illumination and temperatures. For the PERT A and B modules, we have condensed over 49,000 and 42,000 I-V curves each, respectively, taken between January 2002 and July 2008. For the HVST2 array modules, we have distilled over $57,000 \mathrm{I}-\mathrm{V}$ traces, for each of the positive and negative strings, taken between April 2005 and July 2008. The HVST2 array data set is larger, because the curves are dually traced: going from Voc to Isc and then back from Isc to Voc for each scheduled measurement. The field data are numerically analyzed, segregated into bins of irradiance $50 \mathrm{~W} / \mathrm{m}^{2}$ wide, evaluated at reference temperature $\left(25^{\circ} \mathrm{C}\right)$, and partitioned into $2-3$ month-long semesters, thereby allowing for the temporal scrutiny of all parameters The statistical variances of the temporally partitioned data sets range between 10 and 30 days for each irradiance, so a large amount of signal averaging is achieved, with the goal of retaining sufficient detail across all illuminations for each time interval. Spectral effects are one of the few field conditions remaining that can modify module performance, have not been fully accounted for: yet, we can expect that some manifestation of spectral effects may become noticeable due to our analysis and signal averaging executed over time partitions where congruent spectral conditions in the field exist.

\section{DATA}

\subsection{Free-standing, long-term outdoor testbed modules measured at STC}

In Fig. 2, we portray the performance and I-V power parameters measured indoors on SPIRE or LACSS simulators for both types of CIS modules (A and B) as a function of time. Fig. 2 is a composite-panel graph depicting the efficiency, FF, Voc and Isc data, respectively, starting from the bottom-most pane and working up, plotted vs. time. The abscissae for the Isc and Voc data panes, respectively, at the top and second-from-top panes exhibit scale changes used to depict disparate current and voltages obtained for the various modules. Fig. 2 shows data for A or B modules beginning in 1988 or in 2002, respectively. Also depicted are data for a 1997 A and 2002 B module deployed on PERT, occasionally tested indoors. The A modules represent five separate epochs encompassing changes made to the baseline CIS process by the manufacturer between 1988 and 1998. The initial efficiency of the A modules is about $8 \%$ in 1988, which improved over time to $11 \%-12 \%$; the initial B module efficiency is about $11 \%$. The efficiency data of A modules from the 1990-1992 era appear stable, but later vintage A-module data are less stable. One of the 1988 A modules was removed and returned to manufacturer in 1998 after dropping precipitously to $\sim 6 \%$ efficiency; the other 1988 A module has held up better, undergoing a cumulative change in efficiency from about $8 \%$ to $5.9 \%$ over a 20 -year period, or equivalently $1.3 \%$ relative loss per year. From Fig. 2 we observe some abrupt changes to module performance: in 1990 a hardware revision altered the data for the 1988 A modules, resulting in a sharp drop of $0.5 \%$ in efficiency, without which the loss rate would be only $1.0 \%$ per year $(\% / y r)$. This illustrates some of the difficulties encountered in accurate testing methodology at STC over the long-term, especially for Isc measurements. The relative performance loss rates for the modules shown in Fig. 2 range from negligible for 1990 A modules, to $-2.2 \% / y r$ for the 1998 A modules. The B modules depicted in Fig. 2 appear more stable, exhibiting a cumulative loss of less than $0.5 \%$ absolute, less than $1 \% / \mathrm{yr}$ relative loss rate, albeit, this is based on only 6 years of exposure data. Fig. 2 shows the primary mode of degradation for A modules is FF loss, followed by some Voc decline when tested at STC. However, Voc data appear to exhibit slight improvement after the initial few years of deployment for A modules made on or before 1992, followed by subsequent loss afterward. Similarly for B-module data, there are some FF losses with time, plus transient, slight improvement in Voc values initially just after deployment.

The data in Fig. 2 expose a pattern that reflects transient change upon exposure: initially module performance may not degrade very much with time, due to FF losses that are in part offset by increases in Voc; but then years afterward when Voc losses begin to accrue, the degradation becomes more apparent. In addition, data for the 1997 A module — resident of the PERT, but measured indoors at STC -indicate significant transient or metastable electrical behavior: $\sim 10 \%$ relative improvement in performance occurs due to FF changes between tests conducted in 2006 and 2007. This transient change occurred while this module lay indoors under low light levels at room temperature, during PERT system renovation. Some of this transient behavior in performance also appears in the PERT data shown in subsection 3.2. 


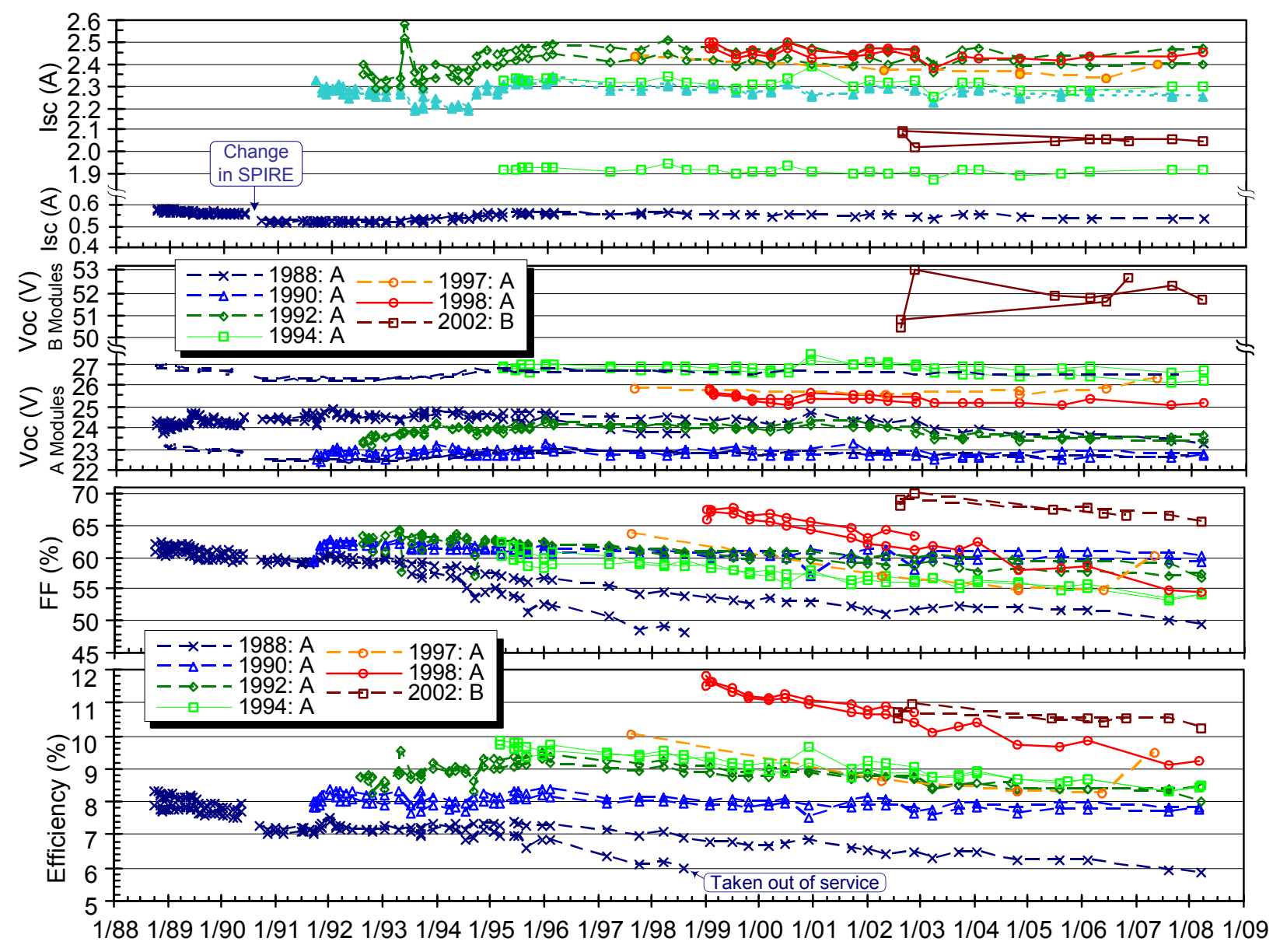

Figure 2. Module performance measured at STC plotted against time, showing Isc, Voc, FF, and efficiency data, respectively, at top, second from top, second from bottom, and bottom panes of the composite graph.

The series resistance data under dark conditions and STC were derived for these modules as referenced [8]: a sample set of 3-point slopes $\mathrm{dV} / \mathrm{dJ}$ plotted against $1 / \mathrm{J}$ for the dark characteristics, or $1 /\left(\mathrm{J}+\mathrm{J}_{\text {Light }}\right)$ for light data, are shown in Figure 3, for a 1994 A module and a 2002 B module, respectively, in left and right portions of the figure. These data are normalized and reduced to the unit-area cell level. We plot and read the dark characteristics along the lower ordinate and light characteristics in reverse order along the upper ordinate axes in order to facilitate depiction of both data for each module. The changes observed over time are illustrated by showing data taken over several years, denoted by two-digit numbers (e.g., 99, 02, 05, 07, etc., are the year the measurements were taken) to show the evolution of values. Also, in the figure legends, 'Drk' or 'Lit' refer to slopes derived from dark or light J-V data, respectively. For the 1998 A module in the left-hand pane, substantial increases in series-resistance values occur over time, about $4 \mathrm{ohm}-\mathrm{cm}^{2}$ or $1-2 \mathrm{ohm}-\mathrm{cm}^{2}$, respectively, for dark or light data. The data for the $2002 \mathrm{~B}$ module in the right pane exhibit substantial non-linear characteristics that appear to exacerbate over time (2002 to 2008) for the dark dV/dJ data, but to lesser extent in the light. The curvature for the 2002 B data complicate the analysis: even though the slope of the characteristics $-\mathrm{dV} / \mathrm{dJ}$ vs. $1 / \mathrm{J}-$ get steeper, the intercept values do not appear to alter significantly with time, suggesting that the changes are not likely due to series resistance. For the 1998 A module, the data exhibit slight non-linear behavior in far forward bias in the dark, which may indicate development and appearance of a reverse-bias barrier [8] for the device, but whose effect appears to diminish under light. We emphasize that because Jsc values are notably larger for the A modules $\left(30 \mathrm{~mA} / \mathrm{cm}^{2}\right.$ at STC) than for the B modules $\left(24 \mathrm{~mA} / \mathrm{cm}^{2}\right.$ at STC), that even with comparable values of series resistance, resistance increments will impact A module performance more adversely than the $\mathrm{B}$ module. 

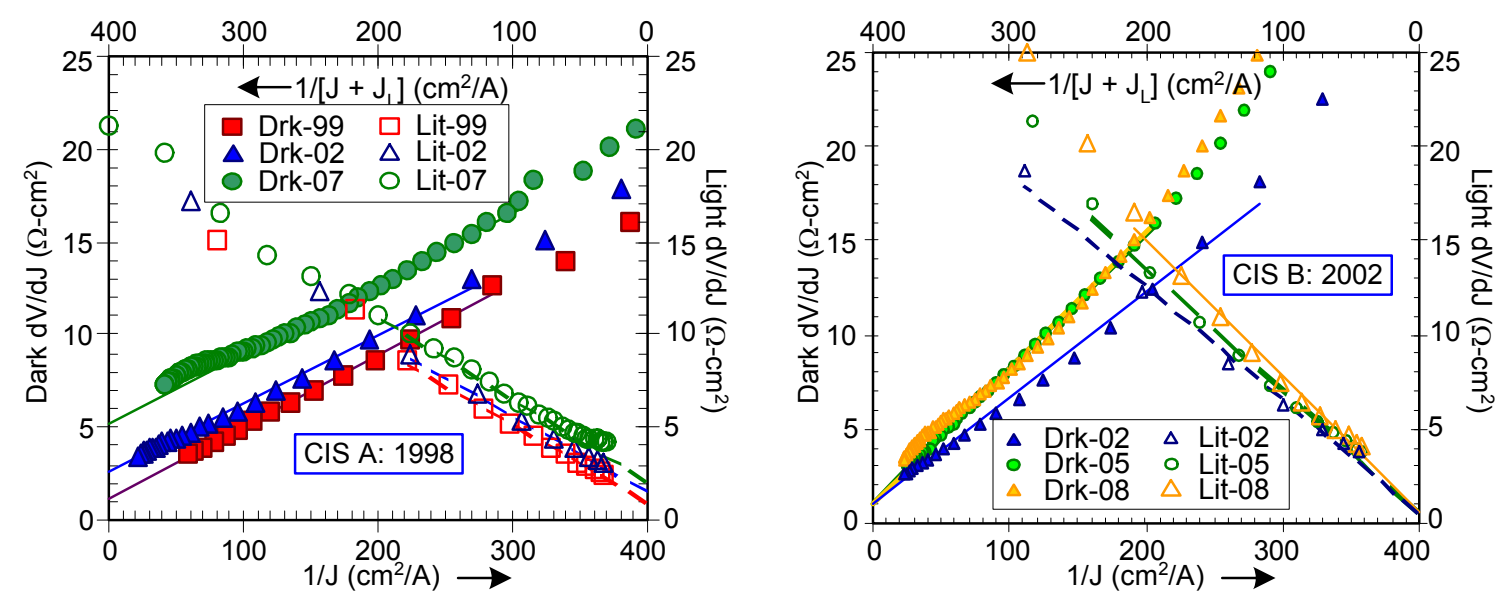

Figure 3. 3 Point slopes $\mathrm{dV} / \mathrm{dJ}$ of dark and light J-V characteristics, plotted either vs. $1 / \mathrm{J}$, or $1 /\left(\mathrm{J}+\mathrm{J}_{\text {Light }}\right)$, for 1998 A and 2002

B modules, respectively, shown in left- and right-hand panes. The dark data are read along the lower ordinate, the light data are plotted in reverse order and read along upper ordinate axes.

The changes in series-resistance values so derived under dark conditions or STC data are summarized and portrayed in Figure 4 as a function of time for dark and light data, between 1999 and 2008, for representative A and B modules. Smoothed solid or dashed lines have been drawn manually to serve as a guide for the trends observed. For the A modules portrayed: significant increases are observed in the dark series resistance over the course of several years, ranging 1 to 4 $\mathrm{ohm}-\mathrm{cm}^{2}$; while the series resistance values at STC typically exhibit lesser increase, about 1 to $1.5 \mathrm{ohm}-\mathrm{cm}^{2}$. We emphasize the observed substantial drop in series resistance for the 1997 A module: this transient change occurred while the module lay indoors for a year between 2006 and 2007. These changes are reflected in transient improvement of the performance of both STC and PERT field data shown later. For the B module, the series resistance data exhibit ambiguous changes with time, which is an ambiguity largely arising from the choice of fitting interval in the extrapolation coupled with the non-linear $\mathrm{dV} / \mathrm{dJ}$ characteristics for this module.

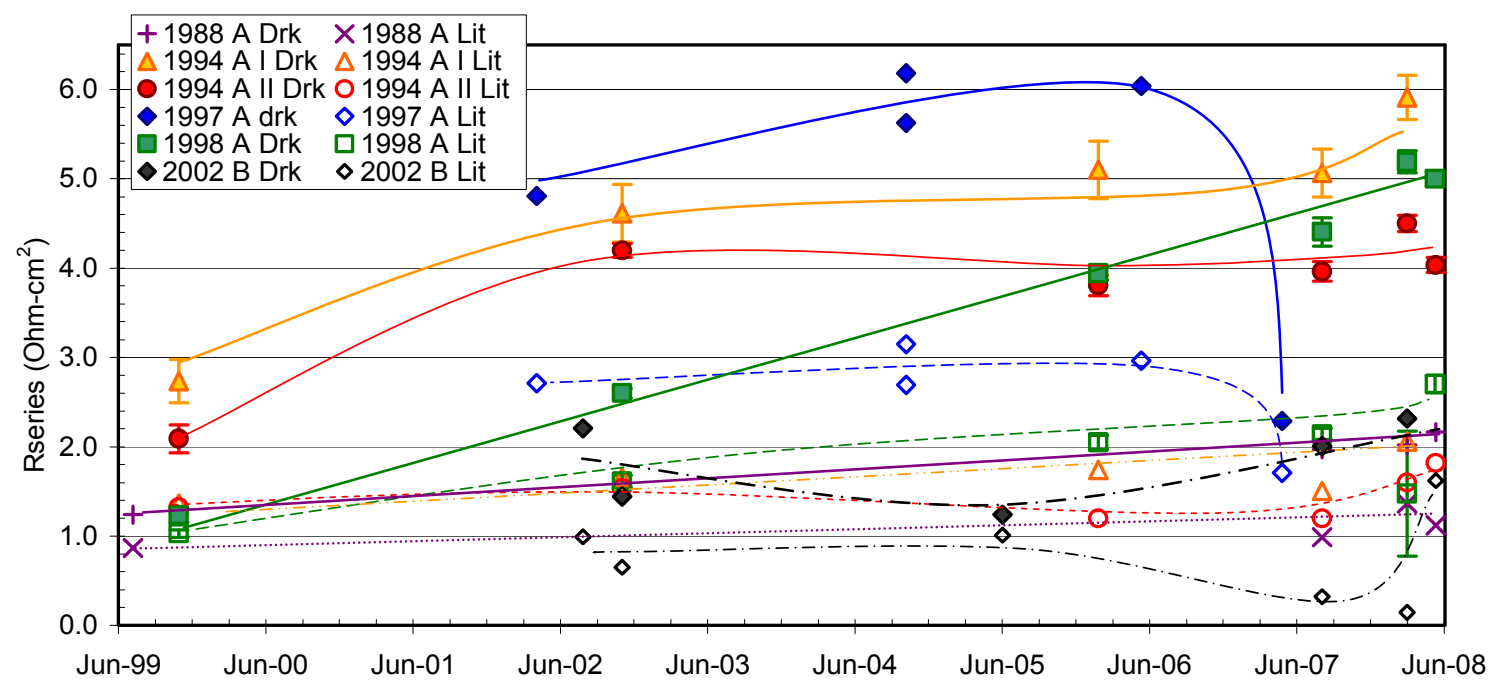

Figure 4. Summary of derived dark or light series-resistance values for A and B modules, respectively, from dark conditions or STC J-V characteristics, plotted against time. Trend lines are manually drawn to indicate approximate changes.

Values of module shunt conductance (Gsh) were derived from 3-point slopes of current density with respect to voltage, $\mathrm{dJ} / \mathrm{dV}$, near the origin ( 0 volts) with voltage, and taken as the minima in $\mathrm{dJ} / \mathrm{dV}$ from the dark $\mathrm{J}-\mathrm{V}$ characteristics of such curves. Those slopes and calculations are not presented, but we note in passing that over time, the Gsh data appear to increase more significantly for the B modules than for most of the A modules, which seems to be an observed trend: A 
modules are less afflicted by shunt losses than B modules. In either case however, the Gsh do not appear inordinately large, being less than 1 millisiemens per $\mathrm{cm}^{2},\left(\mathrm{mS} / \mathrm{cm}^{2}\right)$, for most cases, A or B. Corrections to J derived from the shunt, and for $\mathrm{V}$ derived from series resistance, were then applied to the $\mathrm{J}-\mathrm{V}$ traces for further diode analysis. Thus we arrive at values for the reverse saturation current density $\left(\mathrm{J}_{0}\right)$ plus the diode quality factors under dark and light (STC) conditions as portrayed in Fig. 5, respectively, in left and right portions of the figure, plotted against time between 1999 and 2008. The diode quality factors are derived from the $\mathrm{dV} / \mathrm{dJ}$ vs. $1 / \mathrm{J}$, or $1 /\left(\mathrm{J}+\mathrm{J}_{\text {Light }}\right)$ under dark or light characteristics, respectively, while the $J_{0}$ were calculated from extrapolation of the dark $\log (J)-V$ curves to the origin. Similarly, smoothed solid or dashed lines have been drawn manually to serve as a guide for the observed trend changes. Referring to the left-hand pane of Fig. 5, the $\mathrm{J}_{0}$ data do not appear to indicate substantial changes in this parameter over time for most of the A modules: in the 1988 A, it is negligible, while for the 1998 A module it varied by about a factor of 3. This statement is made after consideration that altering the fitting range of $\log (\mathrm{J})-\mathrm{V}$ traces in the extrapolation can result in multiplicative changes in $\mathrm{J}_{0}$ of $50 \%$. Conversely, for the $2002 \mathrm{~B}$ module, changes in $\mathrm{J}_{0}$ look more substantial, varying by a factor of $\sim 40$. For this module, the diode quality factor appears to alter significantly over time as observed in the righthand portion of the graph. The increments in diode quality factors for the A modules are between negligible and $20 \%$ over 8 years time, with $10 \%$ being a typical variation. Although the changes observed for the $2002 \mathrm{~B}$ module appear more substantial, perhaps increasing $30 \%$ over 5 years, they may be more indicative of changes in the rectification nature of this device: a weakening of the primary diode and strengthening of a diode at low voltage.
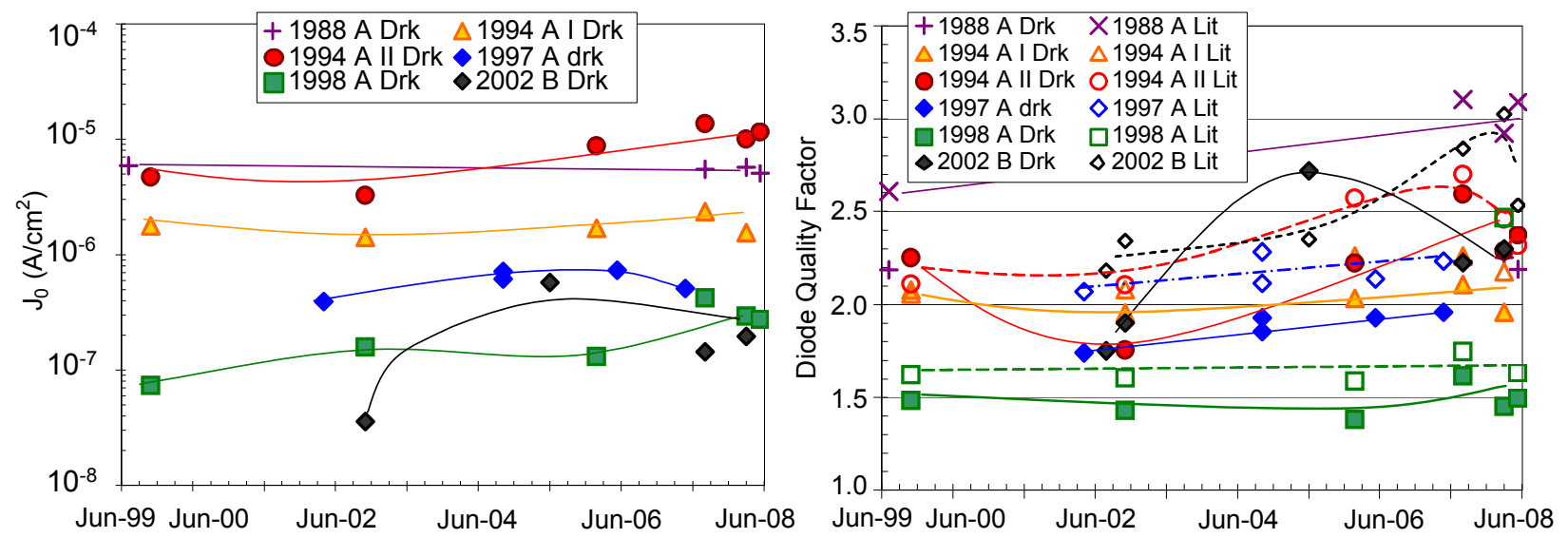

Figure 5. Reverse saturation current density $\mathrm{J}_{0}$ (dark) and diode quality factors derived from $\mathrm{J}-\mathrm{V}$ ( dark and light) data, respectively, at left and right portions of the graph, plotted against time for select A and B modules.

\subsection{PERT system field data}

We portray the I-V power parameters against time as the ordinate, for 1997 A and 2002 B modules, respectively, in left and right portions of Fig. 7: a composite multi-pane graph, showing the efficiency, FF, Voc, and Isc, going from the bottom to top panes, evaluated at $25^{\circ} \mathrm{C}$ reference temperature in all cases. Only data measured from 2002 onward are analyzed or presented, but we note the 1997 A module has been deployed on the PERT since 1997; while the 2002 B module was installed in 2002. All I-V traces were numerically condensed to the power parameters or slopes at open- and closed-circuit conditions after binning into irradiance bins across all illuminations and partitioning the data further into 3month semesters, evaluating all parameters within such time intervals. This analysis greatly reduces the noise that is inherently and typically observed in outdoor data. Note: the abscissae for the respective two modules' data span somewhat different scales, in order to highlight changes. The Voc and Jsc data are normalized to the unit cell area, with their abscissae marked in units of millivolts and milliamps per $\mathrm{cm}^{2}$, respectively. Data in each of three separate irradiance ranges, all averaged over $\pm 75 \mathrm{~W} / \mathrm{m}^{2}$ spans, are depicted going from low $250 \mathrm{~W} / \mathrm{m}^{2}$, through mid $500 \mathrm{~W} / \mathrm{m}^{2}$, and up to high $1000 \mathrm{~W} / \mathrm{m}^{2}$ irradiance, to help illustrate the source(s) of some of the losses. Temporal variations aside, there are salient differences in power parameters observed for the two modules: 1) the B module efficiency data are larger than the A module's, and their separation between lower and higher irradiance is also much greater, about $2 \%$ absolute, versus typically $1 \%$ or less for the A module; 2 ) the FF values for the A module at the three irradiance levels are consistent with series-resistance limited performance, with lower FF at higher irradiance and vice-versa, whereas the B module's FF data are more typical of those reflecting shunt-limited behavior (i.e., the higher the irradiance the higher the FF); and 3) the Voc and Jsc data suggest that the bandgap - and hence the amount of gallium or sulfur alloying-is substantially higher for the B module than for the A module. 

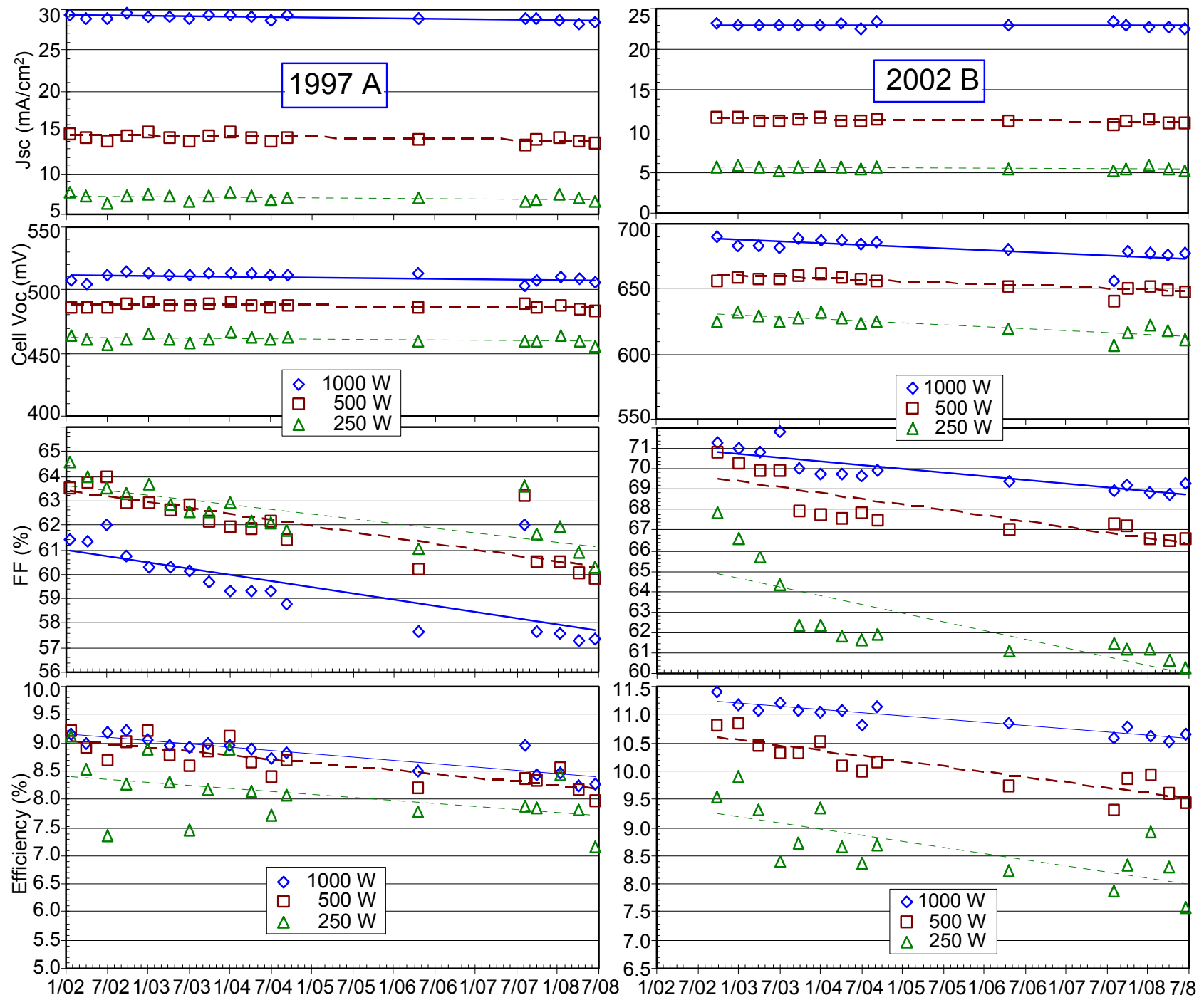

Figure 6. I-V power parameters at $25^{\circ} \mathrm{C}$ distilled from PERT data, plotted vs. time, for 1997 A module at left and 2002 B module at right, showing efficiency, FF, cell Voc and Jsc, respectively, going from the bottom panes to the top panes.

In each of the individual panes, the linear trends with time for each of the power parameters are also depicted, calculated by linear regression, for each irradiance level. Note for the B module at $250 \mathrm{~W} / \mathrm{m}^{2}$ irradiance, the FF data dropped more abruptly from about $68 \%$ to $62 \%$ within the first year of exposure - July 2002 to 2003 - than it did in the five succeeding years since, where it has only dropped by at most another $2 \%$, so that a linear loss rate with time is probably not the most accurate description. As discussed previously, we draw attention to the peculiar behavior of the data for the $1997 \mathrm{~A}$ module, immediately after returning it to the PERT rack in August of 2007: a large discrepancy occurs in FF data at this time, especially at the mid to higher irradiance where values are displaced by $4 \%$ to $6 \%$ above the linear trend lines. This change appears to be transient and disappears after several months.

For the A module, it appears that FF degradation comprises the primary losses observed: loss rates in each illumination window are very similar, and Voc losses are negligible. Conversely for the B module, we obtain two appreciable loss modes: FF declines constitute the primary loss mode - between $0.4 \%$ and $0.8 \%$ per year-but degradation in Voc data are also palpable, ranging between 2.3 and 2.8 millivolts loss rate per year for each cell. The loss modes for each of the power parameters are better quantified via linear regression against time: these are summarized below in Table 1 for both modules - the A module toward the left and B module toward the right of the table-expressed in percent change per year $(\% / y r)$ from initial values; the statistical sizes of \pm 1 standard deviations of each rate parameter are listed along with 
each entry (also in \%/yr). Values determined within each respective illumination band are tabulated under each column designated by the center irradiance along the top row. Inspection of loss rates listed in Table 1 show that at 1-sun, the 1997 A module is losing performance at a rate of $1.3 \% / \mathrm{yr}$, slightly higher than the $2002 \mathrm{~B}$ module which is degrading at $1 \% / \mathrm{yr}$. However, the loss rates at lower irradiance ranges for the B module are significantly larger than those of the A module: within the $500 \mathrm{~W} / \mathrm{m}^{2}$ and $250 \mathrm{~W} / \mathrm{m}^{2}$ irradiance bands, the performance of the B module degrades at $1.8 \% / \mathrm{yr}$ and $2.3 \% / \mathrm{yr}$, respectively; while those of the A module decline by only $1.5 \% / \mathrm{yr}$ and $1.3 \% / \mathrm{yr}$. Hence, because the energy yield from modules erected at fixed latitude tilt comprises an integration of a substantial amount of irradiance frequencies at lower intensity levels, it is likely that on an energy yield basis, both A and B modules may appear to be declining at the same rate. From Table 1, the dominant loss modes for the B module at high- and mid-level irradiance bands are comprised first by FF decline, followed then by Voc loss; whereas for the A module, the losses in FF are dominant at high irradiance, followed by Jsc losses. Surprisingly, this analysis would indicate that current losses constitute a substantial portion of the loss rates for both modules, especially from mid- to low-level irradiance, expressing nearly identical loss rates in Jsc of about $0.7 \% / \mathrm{yr}$. A fundamental difference between the two modules is that the Voc loss rate for the A module is negligible, about $0.1 \% / \mathrm{yr}$ across all illumination levels.

Table 1. Summary of rate changes in I-V power parameters in three irradiance windows, for 1997 A module in left-hand columns and 2002 B module in right-hand columns, in descending order of efficiency, FF, Voc, and Jsc

\begin{tabular}{|c|c|c|c|c|c|c|c|c|}
\hline & Module & $\begin{array}{c}250 \mathrm{~W} / \mathrm{m}^{2} \\
(\% / \mathrm{yr})\end{array}$ & $\begin{array}{c}500 \mathrm{~W} / \mathrm{m}^{2} \\
(\% / \mathrm{yr})\end{array}$ & $\begin{array}{c}1000 \mathrm{~W} / \mathrm{m}^{2} \\
(\% / \mathrm{yr})\end{array}$ & Module & $\begin{array}{c}250 \mathrm{~W} / \mathrm{m}^{2} \\
(\% / \mathrm{yr})\end{array}$ & $\begin{array}{c}500 \mathrm{~W} / \mathrm{m}^{2} \\
(\% / \mathrm{yr})\end{array}$ & $\begin{array}{c}1000 \mathrm{~W} / \mathrm{m}^{2} \\
(\% / \mathrm{yr})\end{array}$ \\
\hline Eff & \multirow{4}{*}{$1997 \mathrm{~A}$} & $-1.3 \pm 0.08$ & $-1.5 \pm 0.04$ & $-1.3 \pm 0.03$ & \multirow{4}{*}{2002 B } & $-2.3 \pm 0.09$ & $-1.8 \pm 0.04$ & $-1.0 \pm 0.02$ \\
\hline FF & & $-0.60 \pm 0.13$ & $-0.75 \pm 0.13$ & $-0.84 \pm 0.20$ & & $-1.31 \pm 0.29$ & $-0.80 \pm 0.15$ & $-0.51 \pm 0.09$ \\
\hline Voc & & $-0.07 \pm 0.00$ & $-0.05 \pm 0.00$ & $-0.13 \pm 0.00$ & & $-0.45 \pm 0.00$ & $-0.35 \pm 0.00$ & $-0.38 \pm 0.00$ \\
\hline Jsc & & $-0.68 \pm 0.06$ & $-0.71 \pm 0.06$ & $-0.37 \pm 0.04$ & & $-0.74 \pm 0.04$ & $-0.72 \pm 0.04$ & $-0.13 \pm 0.05$ \\
\hline
\end{tabular}

The underlying causes for the decreases in FF data are investigated further by analyzing the time evolution of the series resistance and diode quality factors for these two modules: these are depicted in Fig. 7, with series-resistance data on the left and diode quality factors on the right, plotted against time between 2002 and 2008, for PERT A and B modules. The series-resistance data are not normalized and represent the values for the entire modules; the diode quality factors represent the average values for each cell. The sizes of \pm 1 standard deviations in the derived parameters are portrayed for each individual point. These particular data reflect the derivations from Roc-1/Isc regression analyses for irradiance ranges above one-third of 1-sun; albeit the analyses were repeated with varying fitting ranges inclusive down to 200 $\mathrm{W} / \mathrm{m}^{2}$ and do not alter any of the results significantly, except for the size of the statistical error. The linear trends that were analyzed for these data by regression with time are also depicted. From Fig. 7, we can conclude that the series resistance of the A module appears to increment from 1.3 to about $1.7 \mathrm{ohms}$, whereas that of the B module appears unchanged within the size of statistical error, remaining close to $1.3 \mathrm{ohms}$. The linear trends in diode quality factors on the right of Fig. 7 indicate an increase with time of about 0.4 for the A module; and 0.1 for the B module, slightly above statistical significance. The linear rate increments in these data amount to $2.5 \% / \mathrm{yr}$ and $0.7 \% / \mathrm{yr}$, respectively, for the A or $\mathrm{B}$ module; the statistical error for each rate is $\sim 0.2 \% / \mathrm{yr}$.
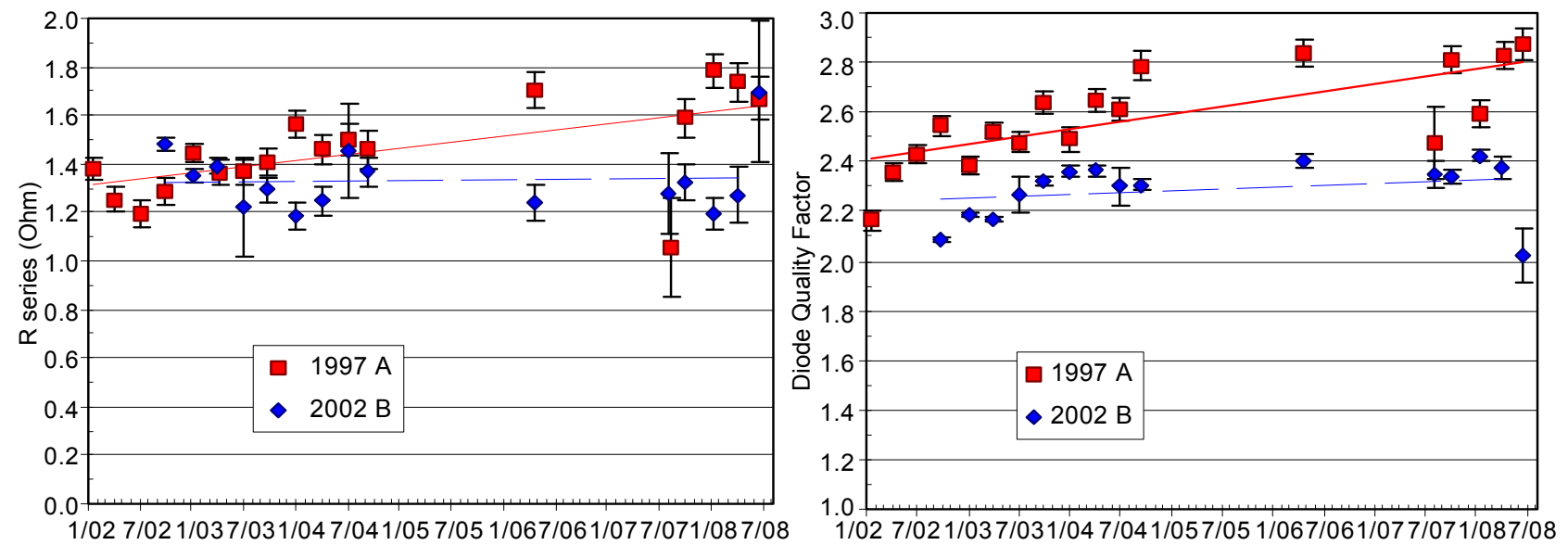

Figure 7. Series resistance and average diode quality factors depicted in left and right portions of the figure, respectively, derived from Roc-1/Isc regression of field data above $300 \mathrm{~W} / \mathrm{m}^{2}$, for $1997 \mathrm{~A}$ and $2002 \mathrm{~B}$ modules, plotted against time. 


\subsection{High-voltage stress test array field data}

The I-V power parameters distilled via linear regression for both negative and positive strings of the HVST2 array are portrayed, respectively, in left- and right-hand portions of Fig. 8, against time as the ordinate. Similar to Fig. 7, Fig. 8 is a composite multi-pane graph, showing the efficiency, FF, Voc, and Isc, going from bottom-most to top-most panes, evaluated at $25^{\circ} \mathrm{C}$ reference temperature in all cases; but the data plotted are values obtained for the respective strings, without any of the normalization to the cell or module level. Also, data obtained in each of three separate irradiance windows, all $\pm 75 \mathrm{~W} / \mathrm{m}^{2}$ wide, are depicted starting at low $250 \mathrm{~W} / \mathrm{m}^{2}$, through $\mathrm{mid} 500 \mathrm{~W} / \mathrm{m}^{2}$, and up to high $1000 \mathrm{~W} / \mathrm{m}^{2}$ irradiance. The ordinate axes in Fig. 8 span the time between April 2005 and July 2008. Each respective abscissae (e.g., Voc, Isc, etc.) portray comparable absolute ranges, at left or right. Trend lines calculated via linear regression analyses against time are also depicted for all parameters within each and every irradiance band.
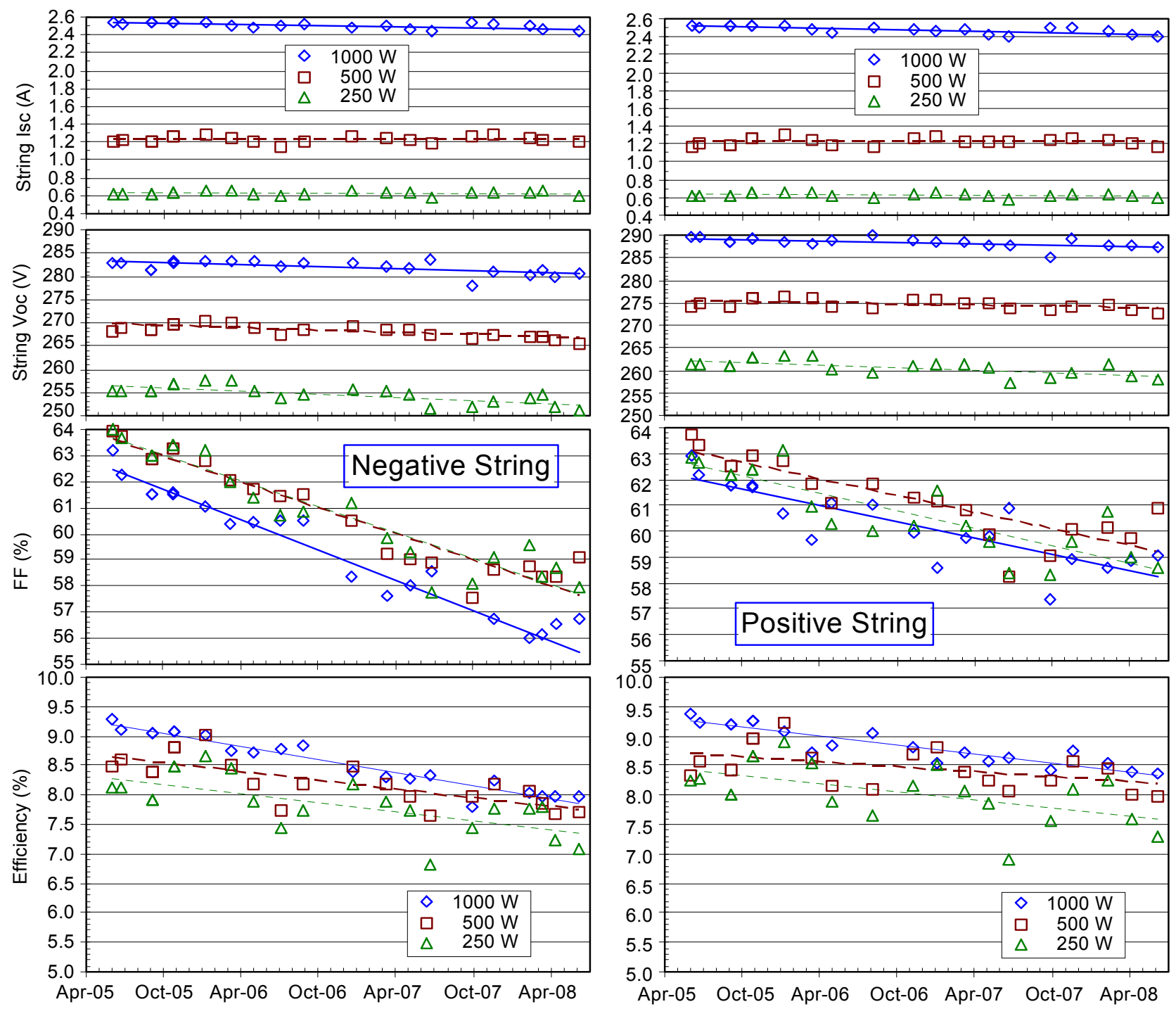

Figure 8. I-V power parameters at $25^{\circ} \mathrm{C}$ distilled from the HVST2 array data, plotted vs. time, for negative and positive strings, respectively, in left- and right-hand portions showing efficiency, FF, string Voc and Isc, respectively, starting from bottom-most and going to top-most panes.

Figure 8 provides a convenient perspective from which to gauge and compare string performance side by side, fundamentally showing that the negative string has suffered definitively larger decay than the positive string, largely as a result of FF degradation, at rates of $40 \%-85 \%$ higher than those of the positive string, depending on irradiance band. The initially efficiency data for both strings were about $9.3 \%-9.4 \%$, and $/$ or $8.3 \%-8.6 \%$, respectively, at $1000 \mathrm{~W} / \mathrm{m}^{2}$, or 
at mid to low irradiance bands. After just over three years of exposure, the efficiency data have decayed about $1 \%$ absolute at $1000 \mathrm{~W} / \mathrm{m}^{2}$ and closer to $1.5 \%$-absolute at mid irradiance.

The loss or change rates determined for all of the I-V power parameters in each string of the HVST2 array, and for all three illumination bands, are quantified via linear regression analysis against time and are listed in Table 2: toward the left side for the negative string, or the right side for the positive string, expressed in $\% / y r$ change from initial values. The statistical sizes of \pm 1 standard deviations of each rate parameter are listed along with each entry (also in \%/yr). Values determined within each respective illumination band are tabulated under each column designated by the center irradiance along the top row. The rates are organized in descending order of efficiency, FF, Voc and lastly Isc, going from top to bottom rows. Inspection of Table 2 shows that performance data for the negative string are decaying at an average rate of $4.0 \% / \mathrm{yr}$, taken over the three irradiance levels; whereas the positive string data are declining at an average rate of only $2.9 \% / \mathrm{yr}$. The difference in degradation rates between the two strings appears to be above the average statistical error of $0.7 \% / \mathrm{yr}$. We observe that the losses comprised primarily declines in FF, followed in significance mostly by Voc loss or occasionally by Isc at high irradiance-Isc loss rates in the lower- to mid-irradiance ranges are indistinguishable from zero and statistically insignificant. This latter ambiguity may arise as a result of not accounting for spectral effects.

Table 2. Summary rates of change of I-V power parameters in three irradiance windows, for the HVST2 array's negative or positive strings, respectively, toward the left- or right-hand sides, in descending order efficiency, FF, Voc, and Isc

\begin{tabular}{|c|c|c|c|c|c|c|c|c|}
\hline & Modules & $\begin{array}{c}250 \mathrm{~W} / \mathrm{m}^{2} \\
(\% / \mathrm{yr})\end{array}$ & $\begin{array}{c}500 \mathrm{~W} / \mathrm{m}^{2} \\
(\% / \mathrm{yr})\end{array}$ & $\begin{array}{c}1000 \mathrm{~W} / \mathrm{m}^{2} \\
(\% / \mathrm{yr})\end{array}$ & Modules & $\begin{array}{c}250 \mathrm{~W} / \mathrm{m}^{2} \\
(\% / \mathrm{yr})\end{array}$ & $\begin{array}{c}500 \mathrm{~W} / \mathrm{m}^{2} \\
(\% / \mathrm{yr})\end{array}$ & $\begin{array}{c}1000 \mathrm{~W} / \mathrm{m}^{2} \\
(\% / \mathrm{yr})\end{array}$ \\
\hline Eff & \multirow{4}{*}{$\begin{array}{c}\text { Negative } \\
\text { String }\end{array}$} & $-3.7 \pm 0.95$ & $-3.4 \pm 0.68$ & $-4.8 \pm 0.29$ & \multirow{4}{*}{$\begin{array}{c}\text { Positive } \\
\text { String }\end{array}$} & $-3.3 \pm 1.15$ & $-2.0 \pm 0.83$ & $-3.3 \pm 0.34$ \\
\hline FF & & $-3.1 \pm 0.24$ & $-3.1 \pm 0.22$ & $-3.7 \pm 0.30$ & & $-2.2 \pm 0.31$ & $-2.0 \pm 0.29$ & $-2.0 \pm 0.30$ \\
\hline Voc & & $-0.52 \pm 0.12$ & $-0.36 \pm 0.07$ & $-0.30 \pm 0.09$ & & $-0.45 \pm 0.12$ & $-0.20 \pm 0.07$ & $-0.21 \pm 0.07$ \\
\hline Isc & & $-0.24 \pm 0.76$ & $0.15 \pm 0.66$ & $-0.99 \pm 0.21$ & & $-0.93 \pm 0.86$ & $0.33 \pm 0.77$ & $-1.13 \pm 0.29$ \\
\hline
\end{tabular}

Finally, we portray each string's series resistance-data and diode quality factors in Fig. 9, respectively, in left or righthand portions of the graph, derived from the intercept and slope of the Roc-1/Isc regression calculated for data taken at irradiance higher than $325 \mathrm{~W} / \mathrm{m}^{2}$. The series-resistance data are not normalized to the cell level, but instead represent cumulative string values. The diode quality factors represent average values for each cell in their respective string, obtained by dividing the slope of the regression by the number of series-connected cells-numbering 504 cells per string. Linear trends in these data are also calculated by regression with time: the data at left indicate that the series resistance of both strings has grown by several ohms, but that of the negative string has outpaced the positive string by about 2 ohms over this time, representing a larger increase of $25 \%$ for the negative string. The growth rates for the series resistance constitute increments of $11 \% / \mathrm{yr}$ and $20 \% / \mathrm{yr}$, for the positive and negative strings, also respectively. The average diode quality factors of the cells in each string appear to be of comparable value initially, about $2.3 \pm 0.1$, but over time have grown at rates of $7.5 \% / \mathrm{yr}$ and $12 \% / \mathrm{yr}$, respectively, for the positive and negative strings; the statistical size of the error in growth rates is $0.4 \% / y r$, so that the determined rates are well above the significance level and also substantially above those of the single modules exposed on PERT.
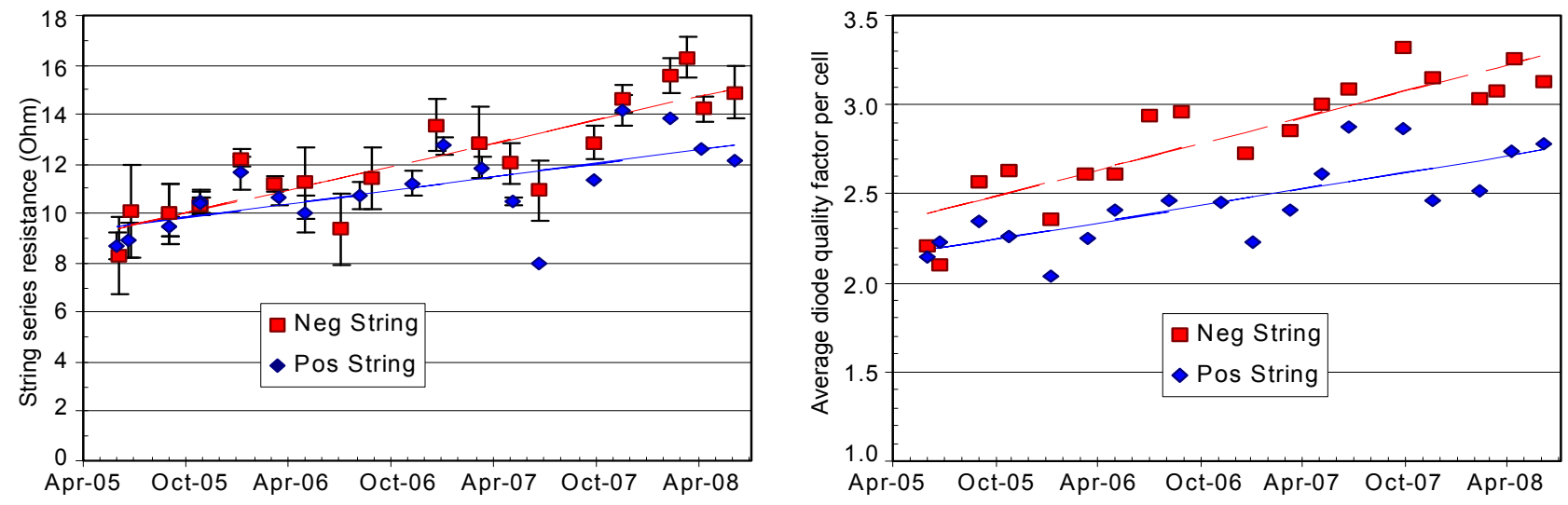

Figure 9. HVST2 array positive and negative strings series resistance and diode quality factors in left and right portions, respectively, derived from Roc-1/Isc regression of field data above $320 \mathrm{~W} / \mathrm{m}^{2}$, plotted against time. 


\section{SUMMARY AND CONCLUSIONS}

Degradation rates for the numerous CIS/CIGS A or B modules exposed outdoors over many years-some for as long as 20 years - were determined under STC or real-time field conditions. The results for the long-term testbed modules measured at STC were previously published [10] and will not be reproduced here, except to note that for the various-era A modules, the degradation rates range from negligible to moderate: $-0.2 \% / \mathrm{yr}$ to $-0.4 \% / \mathrm{yr}$, for $1990-92$ era A modules; $-0.9 \% / \mathrm{yr}$ to $-1.0 \% / \mathrm{yr}$ for 1988 or 1994 era A modules, up to $-2.2 \% / \mathrm{yr}$ for 1998 and later vintage A modules. The data for the long-term testbed 2002 B module exhibit more nuanced changes: palpable degradation loss rates in FF data, about $3 \% / y r$, that for now are largely offset by gains in Voc of $\sim 4.5 \% / y r$. Because measurements at STC are limited in scope and can be misleading, we have focused on performing loss-rate analyses primarily with outdoor field data for the A and B modules that we have installed and connected to data acquisition systems on PERT and on the high-voltage array.

The outdoor field data for the PERT system and bipolar strings of HVST2 array modules were scrutinized in three separate illumination intensity bands that are quite representative of a large span of outdoor lighting: going from low 250 $\mathrm{W} / \mathrm{m}^{2}$, to mid $500 \mathrm{~W} / \mathrm{m}^{2}$, and high $1000 \mathrm{~W} / \mathrm{m}^{2}$ irradiance; each irradiance window comprises measurements over ranges $\pm 75 \mathrm{~W} / \mathrm{m}^{2}$ wide spread about the center value. The loss rates obtained from these more numerous modules over the last 6 years were summarized in Table 1, for PERT A and B modules and in Table 2, for the HVST2 array A modules. When viewed from such an average illumination perspective, the PERT A and B module performance data appear to suffer average loss rates of $-1.3 \% / \mathrm{yr}$ or $-1.7 \% / \mathrm{yr}$, respectively, which are both well above the statistical significance of $0.2 \% / \mathrm{yr}$ error of \pm 2 standard deviations. For the PERT modules, the degradation primarily occurs in the FF data, with Jsc losses of $0.7 \% / \mathrm{yr}$ for both A and B at lower irradiances; and negligible Voc loss for the A and small Voc loss rates for the B of $0.4 \% / \mathrm{yr}$. The HVST2 array loss rates convey an ever more informative picture, showing the average loss rates are either $-4.0 \% / \mathrm{yr}$ or $-2.9 \% / \mathrm{yr}$, respectively, for the negative or positive strings, which may portend more damaging exposure at least for modules configured in negative-string (grounded positive terminal) applications. The HVST2 degradation rates determined in this analysis - averaged over the three illumination levels - are consistent with data published earlier [10] but analyzed using a different method, the PTC regression. Furthermore, we presented data quantifying the primary loss mode for A modules comprising FF degradation largely due to series-resistance increments at rates of $11 \% / \mathrm{yr}$ or $20 \% / \mathrm{yr}$, respectively, for the positive or negative strings; the average diode quality factors of cells in each string are seen to grow at increments of $7.5 \% / \mathrm{yr}$ or $12 \% / \mathrm{yr}$, also for positive or negative strings, respectively. So far, the B modules have not shown significant increases in series resistance for either STC or outdoor data, but yet exhibit FF and Voc losses from other source modes: shunt losses coupled with weakening of the primary diode.

\section{REFERENCES}

[1] I Repins, M A Contreras, B Egass C DeHart, J Scharf, C L Perkins, B To, R Noufi, "19.9\%-efficient ZnO/CdS/CuInGaSe2 Solar Cell with 81.2\% Fill Factor,” Prog. in PV: Res. \& Appl. 16, 2008, pp. 235-239.

[2] C Deibel, V Dyakonov, J Parisi, J Palm, S Zweigart, F Karg, "Influence of damp heat testing on the electrical characteristics of $\mathrm{Cu}(\mathrm{In}, \mathrm{Ga})(\mathrm{S}, \mathrm{Se}) 2$ solar cells," Thin Solid Films, 403-404, 2002, pp. 325-330.

[3] M Schmidt, D Braunger, R Schaffler, H W Schock, U Rau, "Influence of damp heat on the electrical properties of $\mathrm{Cu}(\mathrm{In}, \mathrm{Ga}) \mathrm{Se} 2$ solar cells," Thin Solid Films 361-362, 2000, 283-287.

[4] G A Medvedkin, E I Terukov, Y Hasegawa, K Hirose, K Sato, "Microdefects and point defects optically detected in $\mathrm{Cu}(\mathrm{In}, \mathrm{Ga}) \mathrm{Se} 2$ thin film solar cells exposed to damp and heating," Sol. Ener. Mats \& Sol. Cells 75, 2003, pp. 127133.

[5] J Wennerberg, J Kessler, M Bodegard, L Stolt, "Damp Heat Testing of High Performance CIGS Thin Film Solar Cells," Proc. 2nd WCPEC (1998), Vienna, pp. 1161-1164.

[6] M D Kempe, K M Terwilliger, D Tarrant, "Stress Induced Degradation Modes In CIGS Mini-Modules," $33^{\text {rd }}$ IEEE PVSC, San Diego, CA, May 2008.

[7] J A del Cueto, "Review of the Field Performance of One Cadmium Telluride Module," Prog. In PV: Res. \& Appl., 6, 1998, pp. 433-446.

[8] S S Hegedus, W N Shafarman, "Thin-Film Solar Cells: Device Measurements and Analysis," Progress in PV: Res. \& Appl. 12: 2004; pp. 155-176.

[9] J A del Cueto, "Method for Analyzing Series Resistance and Diode Quality Factors from Field Data of Photovoltaic Modules," Sol. Ener. Mats \& Sol. Cells 55, 1998, pp. 291-297.

[10] J.A. del Cueto, S. Rummel, B. Kroposki, C. Osterwald, A. Anderberg, "Stability Of CIS/CIGS Modules At The Outdoor Test Facility Over Two Decades," 33 $3^{\text {rd }}$ IEEE PVSC, San Diego, CA, May 2008. 


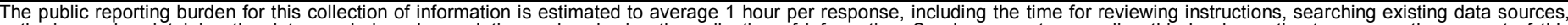

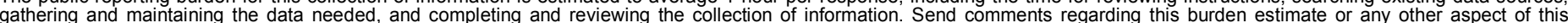

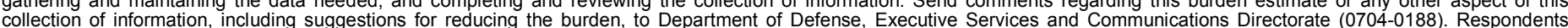

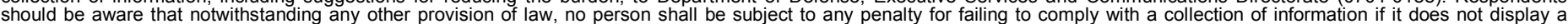

should be aware that notwithstanding

PLEASE DO NOT RETURN YOUR FORM TO THE ABOVE ORGANIZATION.

\section{REPORT DATE (DD-MM-YYYY) \\ November 2008 \\ 2. REPORT TYPE \\ Conference Paper}

4. TITLE AND SUBTITLE

Long-Term Performance Data and Analysis of CIS/CIGS Modules

Deployed Outdoors
3. DATES COVERED (From - To) August 10-14, 2008

5a. CONTRACT NUMBER

DE-AC36-08-GO28308

5b. GRANT NUMBER

5c. PROGRAM ELEMENT NUMBER

5d. PROJECT NUMBER

NREL/CP-520-42856

5e. TASK NUMBER

PVB7.7101

5f. WORK UNIT NUMBER

\section{PERFORMING ORGANIZATION NAME(S) AND ADDRESS(ES)}

National Renewable Energy Laboratory

1617 Cole Blvd.

Golden, CO 80401-3393
8. PERFORMING ORGANIZATION REPORT NUMBER

NREL/CP-520-42856

9. SPONSORING/MONITORING AGENCY NAME(S) AND ADDRESS(ES)

10. SPONSOR/MONITOR'S ACRONYM(S) NREL

11. SPONSORING/MONITORING AGENCY REPORT NUMBER

12. DISTRIBUTION AVAILABILITY STATEMENT

National Technical Information Service

U.S. Department of Commerce

5285 Port Royal Road

Springfield, VA 22161

13. SUPPLEMENTARY NOTES

14. ABSTRACT (Maximum 200 Words)

The long-term performance data of copper indium diselenide (CIS) and gallium-alloyed CIS (CIGS) photovoltaic (PV) modules are investigated to assess the reliability of this technology.

\section{SUBJECT TERMS}

PV; long-term performance, reliability, module; devices; copper indium diselenide; copper indium-gallium-diselenide; open-circuit voltage; large-area; doping density; fill factor

\begin{tabular}{|c|c|c|}
\hline 16. SECURIT & CLASSIFICATI & N OF: \\
\hline $\begin{array}{l}\text { a. REPORT } \\
\text { Unclassified }\end{array}$ & $\begin{array}{l}\text { b. ABSTRACT } \\
\text { Unclassified }\end{array}$ & $\begin{array}{l}\text { c. THIS PAGE } \\
\text { Unclassified }\end{array}$ \\
\hline
\end{tabular}

\begin{tabular}{|c|c|}
\hline $\begin{array}{l}\text { 7. LIMITATION } \\
\text { OF ABSTRACT }\end{array}$ & $\begin{array}{l}\text { 18. NUMBER } \\
\text { OF PAGES }\end{array}$ \\
\hline UL & \\
\hline
\end{tabular}

19a. NAME OF RESPONSIBLE PERSON

19b. TELEPHONE NUMBER (Include area code) 